\title{
Sorafenib increases efficacy of vorinostat against human hepatocellular carcinoma through transduction inhibition of vorinostat-induced ERK/NF-אB signaling
}

\author{
FEI-TING HSU ${ }^{1 *}$, YU-CHANG LIU ${ }^{1,2^{*}}$, I-TSANG CHIANG ${ }^{2,3^{*}}$, REN-SHYAN LIU ${ }^{4}$, \\ HSIN-ELL WANG ${ }^{1}$, WUU-JYH LIN ${ }^{5}$ and JENG-JONG HWANG ${ }^{1}$ \\ ${ }^{1}$ Department of Biomedical Imaging and Radiological Sciences, National Yang-Ming University, \\ Taipei $112 ;{ }^{2}$ Department of Radiation Oncology, National Yang-Ming University Hospital, Yilan 260; \\ ${ }^{3}$ Department of Radiological Technology, Central Taiwan University of Science and Technology, \\ Taichung 40601; ${ }^{4}$ Department of Nuclear Medicine, Taipei Veterans General Hospital, Taipei 112; \\ ${ }^{5}$ Division of Radioisotope, Institute of Nuclear Energy Research, Taoyuan 32546, Taiwan, R.O.C.
}

Received February 15, 2014; Accepted March 24, 2014

DOI: $10.3892 /$ ijo.2014.2423

\begin{abstract}
Sorafenib is effective for patients with advanced hepatocellular carcinoma (HCC) and particularly for those who are unsuitable to receive life-prolonging transarterial chemoembolization. The survival benefit of sorafenib, however, is unsatisfactory. Vorinostat also known as suberoylanilide hydroxamic acid (SAHA) is a histone deacetylase (HDAC) inhibitor with anti-HCC efficacy in preclinical studies. SAHA induces nuclear factor $\kappa$-light-chain-enhancer of activated $\mathrm{B}$ cells (NF- $\kappa \mathrm{B})$ activity in vitro, which may lead to cancer cell progression and jeopardize cytotoxic effect of SAHA in HCC. The goal of this study was to investigate whether sorafenib enhances SAHA cytotoxicity against HCC through inhibition of SAHA-induced NF- $\kappa$ B activity. The human HCC cell line Huh7 transfected with dual reporter genes, luciferase (luc) and thymidine kinase $(t k)$ with $\mathrm{NF}-\mathrm{kB}$ response elements, was
\end{abstract}

Correspondence to: Professor Jeng-Jong Hwang, Department of Biomedical Imaging and Radiological Sciences, National Yang-Ming University, No. 155, Sec. 2, Li-Nong St., Bei-tou, Taipei 112, Taiwan, R.O.C.

E-mail: jjhwang@ym.edu.tw

*Contributed equally

Abbreviations: BCL-2, B-cell lymphoma 2; BLI, bioluminescent imaging; ERK, extracellular signal-regulated kinases; HCC, hepatocellular carcinoma; HDAC, histone deacetylase; luc, luciferase; $\mathrm{NF}-\kappa \mathrm{B}$, nuclear factor $\kappa$-light-chain-enhancer of activated B cells; $r f p$, red fluorescent protein; RFPI, red fluorescent protein imaging; SAHA, suberoylanilide hydroxamic acid; TACE, transarterial chemoembolization; $t k$, thymidine kinase; VEGF, vascular endothelial growth factor; XIAP, X-linked inhibitor of apoptosis protein

Key words: hepatocellular carcinoma, NF-кB, SAHA, sorafenib, vorinostat co-transfected with red fluorescent protein $(r f p)$ gene for noninvasive molecular imaging to assess NF- $\mathrm{\kappa B}$ activity and living cells simultaneously. Cell viability assay, DNA fragmentation, western blotting, electrophoretic mobility shift assay (EMSA) and multiple modalities of molecular imaging were used to assess the combination efficacy and mechanism of sorafenib and SAHA. The administration of high-dose SAHA $(10 \mu \mathrm{M})$ with long treatment time ( $48 \mathrm{~h}$ ) in vitro, and $25 \mathrm{mg} / \mathrm{kg} /$ day by gavage in HCC-bearing nude mice to induce NF- $\kappa \mathrm{B}$ activity were performed. Sorafenib inhibited SAHA-induced NF- $\kappa B$ activity and the expression of NF- $\mathrm{\kappa B}$-regulated effector proteins while it increased the efficacy of SAHA against HCC both in vitro and in vivo. The mechanism of sorafenib to enhance SAHA efficacy on HCC is through the suppression of ERK/NF- $\kappa$ B pathway, which induces extrinsic and intrinsic apoptosis. Combination of sorafenib and SAHA may have the potential as new strategy against HCC.

\section{Introduction}

Hepatocellular carcinoma (HCC) is an endemic disease in Asia and majority of patients are not suitable for curative treatment strategies including surgery, liver transplantation or local ablative therapy, because their symptoms are often at advanced stage (1). Sorafenib is the only effective drug approved by USA Food and Drug Administration to increase overall survival in patients with advanced HCC that are not amenable to transarterial chemoembolization (TACE). However, the survival benefit is far from satisfactory, and more effective new treatment strategy for advanced HCC is needed (2).

Vorinostat or suberoylanilide hydroxamic acid (SAHA) is a histone deacetylase (HDAC) inhibitor, which detaches chromatin from core histone and activates gene transcription. HDAC is overexpressed in HCC cell line and tumor tissues of HCC patients and may be associated with increased invasiveness $(3,4)$. Among HCC patients who received surgical resection or liver transplantation, HDAC overexpression is a 
biomarker for aggressiveness and also a prognostic factor $(5,6)$. Inhibition of HDAC by gene knockdown or inhibitor has been shown with anti-HCC effect in preclinical studies $(3,4,7,8)$. Poor survival in patients with HCC also has been shown with overexpression of $\mathrm{NF}-\kappa \mathrm{B}(9,10)$. It has been observed that low dose SAHA may potentiate $\mathrm{NF}-\kappa \mathrm{B}$ activity $(11,12)$, and may results in $\mathrm{HCC}$ progression through $\mathrm{NF}-\kappa \mathrm{B}$-regulated effector proteins, such as cyclin D1, B-cell lymphoma 2 (BCL-2), $\mathrm{X}$-linked inhibitor of apoptosis protein (XIAP) and vascular endothelial growth factor (VEGF) (13).

Therefore, it is reasonable to combine HDAC inhibitor, such as SAHA, with $\mathrm{NF}-\kappa \mathrm{B}$ inhibitor and the combination effect has been unraveled in many preclinical studies. SAHAinduced apoptosis can be enhanced by $\mathrm{NF}-\kappa \mathrm{B}$ inhibition in hematologic malignancy and breast cancer (14-17). Moreover, bortezomib, which is an anti-NF- $\mathrm{B}$ drug in clinical use, and HDAC inhibitor together have synergistic effect against cell lines of pancreatic cancer and HCC (12). Combination of SAHA and bortezomib has been tested in phase I clinical trials for advanced solid tumors $(18,19)$.

Sorafenib, a targeted drug for $\mathrm{HCC}$, is effective in inhibiting $\mathrm{NF}-\kappa \mathrm{B}$ activation (20). In our previous studies, both constitutive and tumor promoter-induced $\mathrm{NF}-\kappa \mathrm{B}$ activity can be suppressed by sorafenib in vitro and in vivo $(13,21)$. Notably, whether sorafenib enhances the therapeutic efficacy of SAHA through the suppression of $\mathrm{NF}-\kappa \mathrm{B}$ activity remains unknown. The goal of this study was to investigate the effect of sorafenib plus SAHA on NF- $\kappa \mathrm{B}$ activation and tumor growth of HCC in vitro and in vivo by using multimodalities of molecular imaging including bioluminescent imaging (BLI), which can reveal the real-time change of intracellular $\mathrm{NF}-\kappa \mathrm{B}$ signal with times; red fluorescent protein imaging (RFPI), the signal represents the living cells; and whole-body autoradiography to demonstrate the tumor volume (13). In order to study the effect of NF- $\mathrm{NB}$ inhibition on anti-HCC efficacy of SAHA, HCC cells transfected with $\mathrm{I} \kappa \mathrm{B} \alpha$ mutant vector was used as the positive control for effect of $N F-\kappa B$ inhibition.

\section{Materials and methods}

Construction of plasmid vector with $N F-\kappa B$ response element carrying reporter genes herpes simplex virus (HSV) thymidine kinase (tk) and firefly luciferase (luc2). The construction protocol has been published in our previous study (13). In short, CMV-IRES-dsred2 vector (Clontech, Mountain View, CA) was digested by Aquaspirillum serpens (Ase) I and Bacillus megaterium (Bmt) I then blunted by Klenow enzyme to form pIres-dsred2. The NF- $\kappa \mathrm{B}$ responsive element isolated from $\mathrm{pNF}-\kappa \mathrm{B}-l u c$ vector (Clontech) by Micrococcus luteus (Mlu) I and Haemophilus influenzae Rd (Hind) III was blunted by Klenow enzyme and then ligated into pIres-dsred 2 to form the $\mathrm{pNF}-\kappa \mathrm{B}$-ires- $d s r e d 2$ vector. The $l u c 2$, which was isolated from pGL4-luc2 (Promega, Madison, WI) by Bacillus stearothermophilus (Bst) XI and Nocardia otitidis-caviarum (Not) I and blunted by Klenow enzyme, was inserted downstream of $\mathrm{pNF}-\kappa \mathrm{B}$-ires, which was derived from $\mathrm{pNF}-\kappa \mathrm{B}$-ires-dsred 2 after being digested by NotI and Xanthomonas badrii (Xba) I, to form pNF- $\mathrm{B}$-ires-luc2. The HSV1-tk, which was isolated from pORF-HSV1-tk (InvivoGen, San Diego, CA) by HindIII and Escherichia coli RY13 (EcoR) I then blunted Klenow enzyme, was inserted into $\mathrm{pNF}-\kappa \mathrm{B}$-ires-luc 2 to form $\mathrm{pNF}-\kappa \mathrm{B}$ tk-luc2 vector.

Hepatocellular carcinoma (HCC) cell culture. Two human HCC cell lines, Huh7 and Hep3B, were used in this study. Huh7 was kindly provided by Dr Jason Chia-Hsien Cheng at the Department of Radiation Oncology, National Taiwan University Hospital, Taipei, Taiwan. Hep3B was obtained from the American Type Culture Collection (ATCC, Gaithersburg, MD). Both cell lines were maintained in Dulbecco's modified Eagle's medium (DMEM) with supplemental 10\% fetal bovine serum (FBS) and cultured at $37^{\circ} \mathrm{C}$ in a humidified incubator containing $5 \% \mathrm{CO}_{2}$. The Huh7/NF- $\mathrm{BB}-t k-l u c 2 / r f p$ stable clone (transfection procedure as described) was maintained in the same medium as Huh7 with additional $500 \mu \mathrm{g}$ / ml of G418 (Calbiochem, Darmstadt, Hesse, Germany).

Establishment of Huh7/NF- $\kappa$ B-tk-luc $2 / r f p$ stable clone from HCC cell line. Huh7 cells $\left(2 \times 10^{6}\right)$ were seeded in a $10-\mathrm{cm}$ diameter dish for $24 \mathrm{~h}$ prior to transfection. $\mathrm{pNF}-\kappa \mathrm{B}-t k-l u c 2$ vector $(8 \mu \mathrm{g})$ and $16 \mu \mathrm{l}$ of jetPEI ${ }^{\mathrm{TM}}$ solution (Polyplus Transfection, Strasbourg, Alsace, France), diluted with 500 and $484 \mu \mathrm{l}$ of $145 \mathrm{mM} \mathrm{NaCl}$, respectively, were mixed and incubated for $30 \mathrm{~min}$ at room temperature to make the $1000 \mu 1$ jetPEI ${ }^{\mathrm{TM}} / \mathrm{DNA}$ mixture. The mixture was then added to Huh7 cells and incubated at $37^{\circ} \mathrm{C}$ for $24 \mathrm{~h}$ followed by trypsinization, then cultured with DMEM containing $1 \mathrm{mg} /$ ml G418 supplemented with $10 \%$ FBS for two weeks. The surviving clones were isolated and transferred to 96-well plates for cell growth. The expression of $l u c 2$ protein in each clone was assayed using BLI, and re-named as Huh7/NF-кBtk-luc2 cell line.

CAG promoter (composed of CMV enhancer and $\beta$-actin promoter)-driven red fluorescent protein (RFP) vector (National RNAi Core Facility Platform, Academic Sinica, Taipei, Taiwan) was used to transfect Huh7/NF-кB-tk-luc2 cell line with the same strategy as the afore-mentioned protocol. Two weeks after RFP vector transfection, cells with red fluorescence were sorted and isolated by flow cytometry. The isolated cells were transferred to 96-well plates for growth. The RFP expression in each clone was assayed using an IVIS50 Imaging System (Xenogen, Alameda, CA). This bioluminescent cell clone with simultaneous red fluorescence was renamed as Huh7/NF- $\mathrm{BB}-t k$-luc $2 / r f p$ cell line.

Transfection of Huh7/NF- $\kappa B$-tk-luc2 with I $\kappa B \alpha$ mutant vector. Huh7/NF- $\kappa \mathrm{B}-t k-l u c 2$ cells transfected with $\mathrm{I} \kappa \mathrm{B} \alpha$ mutant vector ( $\mathrm{pI}-\kappa \mathrm{B} \alpha \mathrm{M}$, Clontech) was used as the positive control for the inhibition of NF- $\kappa \mathrm{B}$ as compared with that suppressed by sorafenib treatment. In addition, Huh7/NF- $\kappa \mathrm{B}-t k-l u c 2$ cell line transfected with empty vector was used as the negative control for $\mathrm{NF}-\kappa \mathrm{B}$ inhibition.

Extraction of sorafenib. The method for extraction of sorafenib was described in our previous study (21). Briefly, sorafenib was extracted from commercial Nexavar ${ }^{\circledR}$ tablets (Bayer, Leverkusen, North Rhine-Westphalia, Germany) composed of $200 \mathrm{mg}$ sorafenib. The tablet was ground to fine powder and transferred to a 100-ml conical flask. The powder was 
washed with $15 \mathrm{ml}$ deionized distilled water three times to remove water-soluble components; $15 \mathrm{ml}$ ethyl acetate was then used to extract the precipitate three times in order to recover the sorafenib. The organic phases were combined and dried over anhydrous sodium sulfate, followed by evaporation under reduced pressure. The residue was recrystallized with acetone and hexane to yield a white solid extract weighing about $122 \mathrm{mg}$ (60\% recovery). Nuclear magnetic resonance (NMR) spectra were recorded with a spectrometer (Varian Gemini 200; Oxford Instruments, Abingdon, Oxfordshire, UK) to determine the chemical structure of the sorafenib extract. High-performance liquid chromatography (HPLC) was conducted using a PU-2089 plus quaternary gradient pump, equipped with a UV-2075 Plus intelligent UV/VIS detector (Jasco, Tokyo, Kanto, Japan). The 1H-NMR spectrum of the recovered sorafenib was the same as the one reported before (22). More than $98 \%$ chemical purity was achieved for the recovered sorafenib (retention time, $16.2 \mathrm{~min}$ ) as determined with HPLC.

Huh7/NF- $\kappa B$-tk-luc2/rfp tumor bearing animal model. Male nude mice $(n=6$ per group and repeated 3 times, total 72 mice, 4-6 weeks old, purchased from National Laboratory Animal Center, Taipei, Taiwan) were injected subcutaneously with $1 \times 10^{7}$ Huh7/NF-кB-tk-luc $2 / r f p$ cells in the right hind flank. Mice were randomly divided into four groups (Fig. 5): control [vehicle treated with $100 \mu \mathrm{l}$ phosphate-buffered saline (PBS) in $1 \%$ dimethyl sulfoxide (DMSO) daily by gavage], SAHA alone $(25 \mathrm{mg} / \mathrm{kg} /$ day for 21 days by gavage), sorafenib alone ( $20 \mathrm{mg} / \mathrm{kg} /$ day for 21 days by gavage) and combination (SAHA plus sorafenib, $25 \mathrm{mg} / \mathrm{kg} /$ day plus $20 \mathrm{mg} / \mathrm{kg} /$ day for 21 days by gavage). All treatments were administered by gavage. Treatment was initiated when tumor volume reached about $50 \mathrm{~mm}^{3}$. Tumor volume was assayed with digital caliper twice a week and BLI once a week. Mice were sacrificed on day 21 post-treatment for ex vivo EMSA, ex vivo western blotting, and whole-body autoradiography. The animal study protocols complied with institutional animal care and use guideline of National Yang-Ming University, Taipei, Taiwan.

Cell viability assay. 3-(4,5-Dimethylthiazol-2-yl)-2,5-diphenyltetrazolium bromide (MTT, Sigma-Aldrich, St.Louis, MO) was

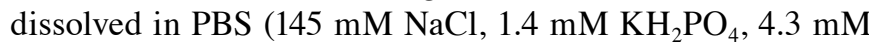
$\mathrm{Na}_{2} \mathrm{HPO}_{4}$ and $2.7 \mathrm{mM} \mathrm{KCl}, \mathrm{pH}$ 7.2). Huh7/NF- $\mathrm{kB}-t k-l u c 2 / r f p$ cells were seeded into 96 -well plates with $3 \times 10^{4}$ cells/well for $24 \mathrm{~h}$, then treated with different concentrations of SAHA (0-10 $\mu \mathrm{M}$ in $0.1 \%$ DMSO) or SAHA combined with $10 \mu \mathrm{M}$ sorafenib for additional $48 \mathrm{~h}$. After washing with fresh medium, $100 \mu \mathrm{l}$ of $5 \mathrm{mg} / \mathrm{ml}$ MTT solution was added to each well followed by incubation at $37^{\circ} \mathrm{C}$ for $2 \mathrm{~h}$. Then $100 \mu \mathrm{l}$ DMSO was added to dissolve the MTT formazan, and the absorbance was determined with an enzyme-linked immunosorbent assay (ELISA) reader (Power Wave X340, Bio-Tek, Winooski, VT) using a wavelength of $570 \mathrm{~nm}$ for excitation.

DNA fragmentation assay. Huh7/NF- $\kappa \mathrm{B}-t k-l u c 2 / r f p$ cells $\left(1 \times 10^{6}\right)$ were seeded in 6-well plates and treated with vehicle (0.1\% DMSO), $10 \mu \mathrm{M}$ SAHA, $10 \mu \mathrm{M}$ sorafenib or combination of both for $48 \mathrm{~h}$. After treatment a genomic DNA purification kit (Axygen, Tewksbury, MA) was used to extract DNA following the instruction provided by the manufacturer. DNA laddering was analyzed with $1.5 \%$ agarose gel electrophoresis.

Electrophoretic mobility shift assay (EMSA). Forty-eight hours post-treatment with vehicle, $10 \mu \mathrm{M}$ SAHA, $10 \mu \mathrm{M}$ sorafenib and combination of SAHA and sorafenib, respectively, nuclear fractions of Huh7/NF- $\kappa \mathrm{B}-t k-l u c 2 / r f p$ cells were obtained using Nuclear Extraction kit (Chemicon, Temecula, $\mathrm{CA})$. The NF- $\kappa \mathrm{B} / \mathrm{DNA}$ binding activity was evaluated using LightShift Chemiluminescent EMSA kit (Thermo Scientific, Rockford, IL). The procedure followed the protocol provided with the kit. In brief, DNA sequences were synthesized for NF- $\kappa$ B binding. Sense: AGTTGAGGGGACTTTCCCAGGC and antisense: GCCTGGGAAAGTCCCCTCAACT. Nuclear extracts were incubated with the biotin-labeled DNA probe for $20 \mathrm{~min}$ at room temperature. The protein-DNA complex was separated from free oligonucleotides on a $5 \%$ polyacrylamide gel, then transferred to a nylon membrane and cross-linked with UV light. The membrane was incubated with streptavidin-horseradish peroxidase, and detected by enhanced chemiluminescence (ECL, Thermo Scientific).

Ex vivo EMSA. Mice were sacrificed on day 21 and tumors were removed for nuclear protein extraction by using Nuclear Extraction kit (Chemicon). The NF- $\kappa \mathrm{B} / \mathrm{DNA}$ binding activity was evaluated using LightShift Chemiluminescent EMSA kit (Thermo Scientific).

Western blotting. Huh7/NF- $\mathrm{B}-t k-l u c 2 / r f p$ cells $\left(2 \times 10^{6}\right)$ were seeded into a $10-\mathrm{cm}$ diameter dish (5 dishes/group) for $24 \mathrm{~h}$ prior to the treatment with vehicle, $10 \mu \mathrm{M}$ SAHA, $10 \mu \mathrm{M}$ sorafenib or combination of $10 \mu \mathrm{M}$ SAHA and $10 \mu \mathrm{M}$ sorafenib, respectively, for another $48 \mathrm{~h}$. Cells were then lysed with $100 \mu \mathrm{l}$ lysis buffer [50 mM Tris- $\mathrm{HCl}$ (pH 8.0), $120 \mathrm{mM}$ $\mathrm{NaCl}, 0.5 \% \mathrm{NP}-40,1 \mathrm{mM}$ phenylmethanesulfonylfluoride]. Total proteins $(40 \mu \mathrm{g})$ were separated by $10 \%$ sodium dodecyl sulfate-polyacrylamide gel electrophoresis (SDS-PAGE), then transferred to a polyvinylidene difluoride membrane (Millipore, Billerica, MA), blocked with 5\% non-fat milk in TBS-Tween buffer (0.12 M Tris-base, $0.15 \mathrm{M} \mathrm{NaCl}$ and $0.1 \%$ Tween-20) for $1 \mathrm{~h}$ at room temperature, and then incubated with primary antibody (Millipore) for XIAP, BCL-2, VEGF, cyclin D1, c-FLIP, caspase-3, caspase-8, cytochrome-C, extracellular signal-regulated kinase (ERK) and $\beta$-actin, respectively, overnight at $4^{\circ} \mathrm{C}$, followed by incubation with secondary peroxidase-conjugated anti-rabbit antibody for $30 \mathrm{~min}$ at room temperature. The expressions of proteins were determined by ECL (Millipore). ImageJ software (National Institutes of Health, Bethesda, MD) was used for the quantitative analysis. A cytosol/nuclear extraction kit (Chemicon) was used to extract cytosolic cytochrome-C following the manufacturer's protocol.

Ex vivo western blotting. Mice were sacrificed on day 21 after treatments. Tumors were removed for protein extraction using T-PER kit (Thermo Scientific). Equal amounts of protein $(40 \mu \mathrm{g})$ were loaded for SDS-PAGE, then transferred to nitrocellulose membranes. The membranes were incubated with primary antibodies specific for VEGF, XIAP, BCL-2, cyclin D1, c-FLIP, caspase-3 and caspase-8, 
A

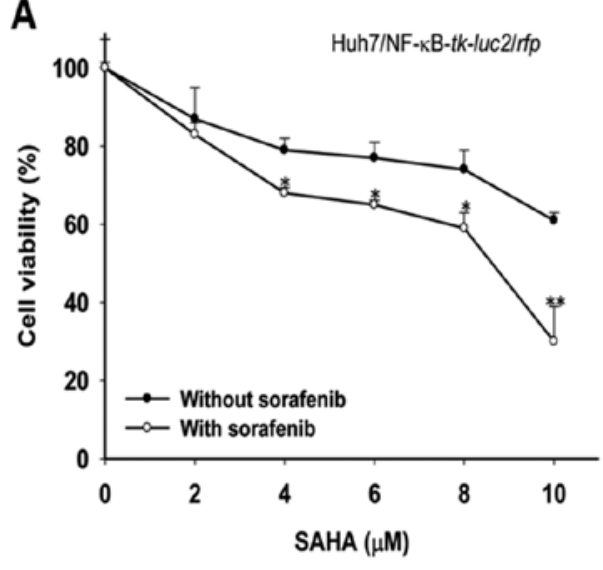

C

Huh7/NF-kB-tk-luc2/np

Ctrl SO SA Comb

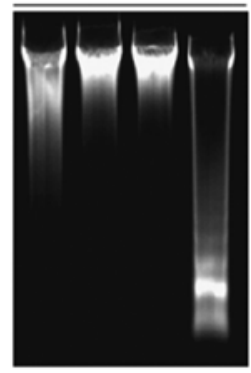

E

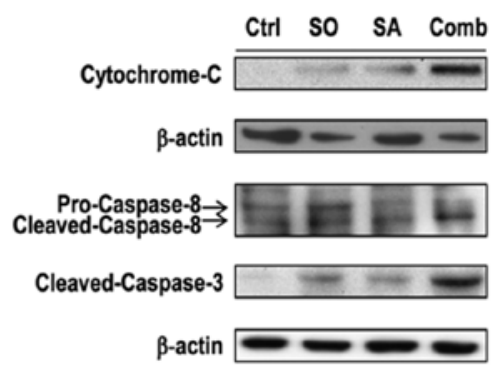

$\mathbf{F}$

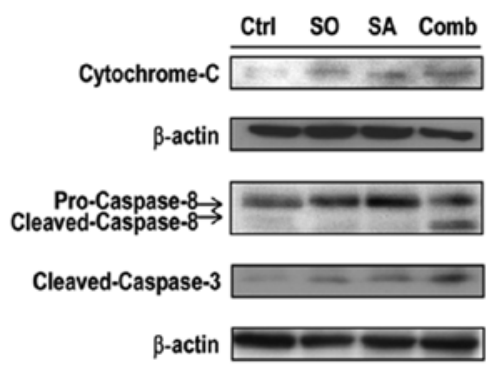

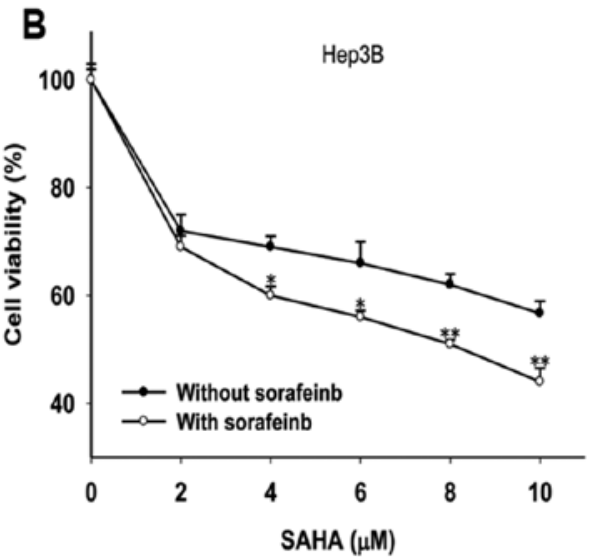

D
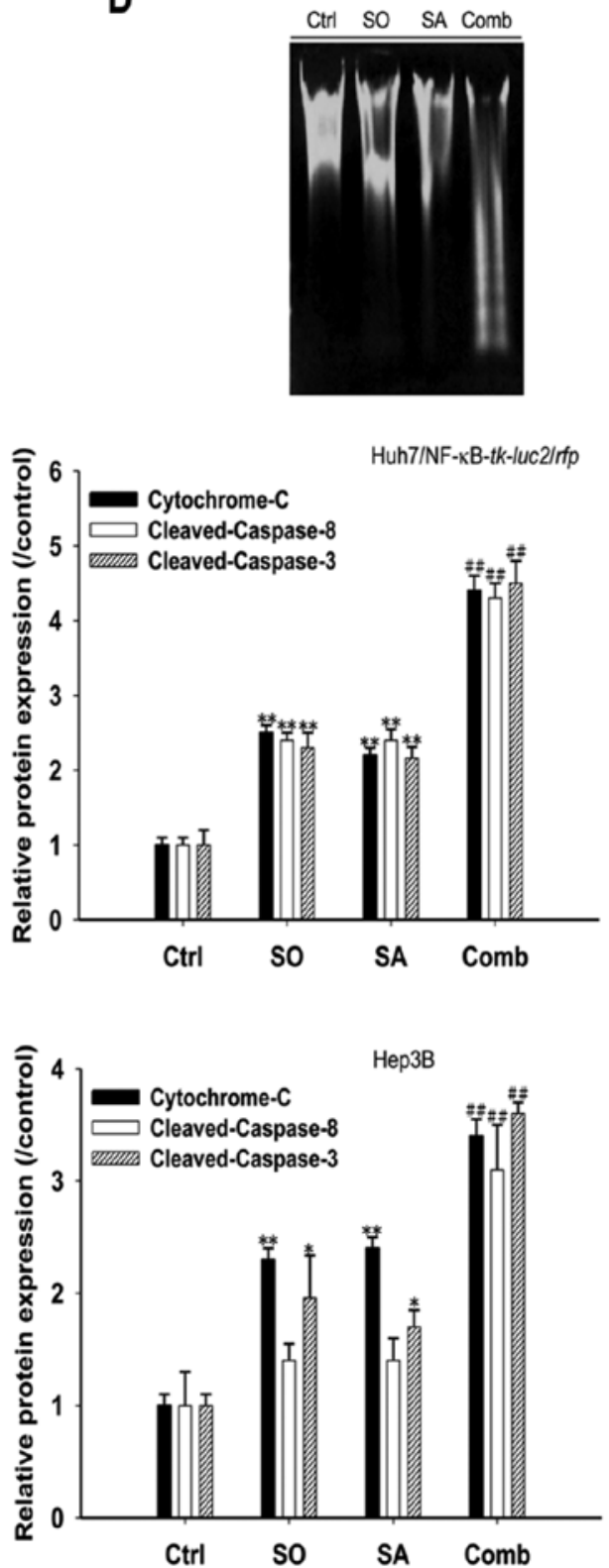

Figure 1. Sorafenib enhances cytotoxicity of SAHA against human HCC (Huh7/NF- $\kappa B-t k-l u c 2 / r f p$ and Hep3B) cells. (A and B) HCC cells were treated with 0-10 $\mu \mathrm{M}$ SAHA alone or combined with $10 \mu \mathrm{M}$ sorafeinb for $48 \mathrm{~h}$ in Huh7/NF-kB-tk-luc2/rfp (A) and Hep3B (B) cells, respectively. MTT assay was used for cytotoxicity. Enhanced cytotoxicity was observed after treatment with $4 \mu \mathrm{M}$ or higher concentrations of SAHA combined with sorafenib. (C and D) HCC cells were treated with SAHA $(10 \mu \mathrm{M})$, sorafenib $(10 \mu \mathrm{M})$ or combination of both for $48 \mathrm{~h}$. DNA laddering, charateristic of apoptosis, was most obvious in

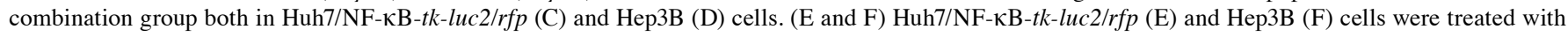
SAHA $(10 \mu \mathrm{M})$, sorafenib $(10 \mu \mathrm{M})$ or combination of both for $48 \mathrm{~h}$. Western blotting was used to evaluate protein expression. Expression of pro-apoptotic proteins were increased after SAHA or sorafenib treatment and most prominent in the combination group. (Ctrl, control; SO, sorafenib; SA, SAHA; Comb, combination; ${ }^{*} \mathrm{p}<0.05,{ }^{* *} \mathrm{p}<0.01$ as compared with that of the control, ${ }^{\# \#} \mathrm{p}<0.01$ as compared with that of sorafenib- or SAHA-treated group). 
cytochrome-C, ERK and $\beta$-actin, followed by incubation with horseradish peroxidase-conjugated secondary antibodies. The protein expression was determined by ECL. A cytosol/ nuclear extraction kit (Chemicon) was used to extract cytosolic cytochrome-C following the manufacturer's protocol.

Therapeutic efficacy evaluation by molecular imaging in vitro and in vivo. Procedure for each modality of molecular imaging was described in our previous study (13). In brief, BLI was used for monitoring the NF- $\kappa \mathrm{B}$ activation in Huh7/ $\mathrm{NF}-\kappa \mathrm{B}-t k-l u c 2 / r f p$ cells. A total of $3 \times 10^{4} \mathrm{Huh} 7 / \mathrm{NF}-\kappa \mathrm{B}-$ $t k$-luc2/rfp cells were cultured in a 96-well plate for $48 \mathrm{~h}$, then treated with various concentrations of SAHA $(0-10 \mu \mathrm{M})$, $10 \mu \mathrm{M}$ sorafenib, combination of SAHA and sorafenib, and $10 \mu \mathrm{M}$ of various signaling molecule inhibitors for $48 \mathrm{~h}$, respectively. D-luciferin (100 $\mu \mathrm{l}$ of $500 \mu \mathrm{M}$, Xenogen) was added to each well for imaging. Relative $\mathrm{NF}-\kappa \mathrm{B}$ activity was calculated as follows: ROI value of treatment group/ROI value of control group, and both ROIs were corrected by cell viability which was determined by MTT assay. BLI was also used in monitoring temporal change of NF- $\kappa \mathrm{B}$ activation in the Huh7/NF- $\mathrm{B}-t k-l u c 2 / r f p$ tumor-bearing mice. Mice were anesthetized using 1-3\% isoflurane and received $150 \mathrm{mg} /$ $\mathrm{kg}$ D-luciferin via intraperitoneal injection $15 \mathrm{~min}$ before imaging. RFPI was used for monitoring viable tumor cell

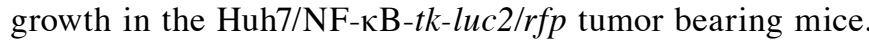
The photons emitted from tumors obtained by BLI and RFPI were detected with an IVIS50 Imaging System (Xenogen). The image acquiring periods for BLI and RFPI were $5 \mathrm{~min}$ and $30 \mathrm{sec}$, respectively. Regions of interest (ROIs) of the images were drawn conformally to the tumor contour and quantified as photons/sec using Living Image software (Version 2.20, Xenogen).

Whole-body autoradiography. Mice were injected intravenously with $3.7 \times 10^{6} \mathrm{~Bq} / 0.2 \mathrm{ml}{ }^{131} \mathrm{I}-1$-(2-deoxy-2fluoro-1-D-arabinofuranosyl)-5-iodouracil (FIAU) on day 21 post-treatments, and sacrificed $24 \mathrm{~h}$ later for whole-body autoradiography. Frontal sectioning was performed with thickness of $30 \mu \mathrm{m}$ at $-20^{\circ} \mathrm{C}$ with a cryostat microtome (Bright Instrument, Huntingdon, Cambridgeshire, UK). Sections were placed on the imaging plate (BAS-SR2040, Fuji Photo Film, Tokyo, Kanto, Japan) in the cassette (2040, Fuji Photo Film). After exposure, the imaging plate was assayed with a FLA5000 reader (Fuji Photo Film) to acquire the phosphor image. The parameters of the reader were: resolution of $10 \mu \mathrm{m}$, gradation of 16 bits, 635-nm laser light and $800 \mathrm{~V}$ of photomultiplier tube.

Statistical analysis. All data were shown as the mean \pm standard error. Student's t-test was used for the comparison between two groups. Differences between the means were considered significant at $\mathrm{p}<0.05$ or less.

\section{Results}

Sorafenib enhances SAHA cytotoxicity through extrinsic and intrinsic apoptotic pathways in HCC. The viabilities of both Huh7/NF- $\kappa \mathrm{B}-t k$-luc2/rfp and Hep3B cells were decreased linearly (Fig. 1A and B) with increasing SAHA concentra- tions (2-10 $\mu \mathrm{M})$ with or without $10 \mu \mathrm{M}$ sorafenib concurrently. Either SAHA or sorafenib alone induced apoptosis through extrinsic (cleaved caspase-8) and intrinsic (cytochrome-C) pathways as unraveled by increased expressions of apoptosisrelated proteins (Fig. 1E and F). Combination of SAHA and $10 \mu \mathrm{M}$ sorafenib not only enhanced HCC cytotoxicity, but accompanied by obvious DNA fragmentation and significantly increased expression of pro-apoptotic proteins (Fig. 1).

Contradictory effects of short (24 h) and long (48 h) treatment time with SAHA on $N F-\kappa B$ activity and expressions of $N F-\kappa B$-regulated effector proteins in Huh7/NF- $\mathrm{B}$-tk-luc2/ $r f p$ cells. After treatments with various concentrations of SAHA for $24 \mathrm{~h}$, the NF- $\kappa \mathrm{B}$ activity was inhibited significantly in HCC cells in a dose-dependent manner (Fig. 2A), and $10 \mu \mathrm{M}$ SAHA reduced effector proteins expressions (Fig. 2B) to $50 \%$ of those of the controls. Notably, SAHA significantly induced $\mathrm{NF}-\kappa \mathrm{B}$ activity in a dose-dependent manner after $48 \mathrm{~h}$ treatments (Fig. 2C), and increased the expressions of $\mathrm{NF}-\kappa \mathrm{B}$-regulated effector proteins by 1.5 - to 2 -fold except cyclin D1 as compared to those of the controls (Fig. 2D).

$N F-\kappa B$ inhibition enhances anticancer effects of SAHA against $H u h 7 / N F-\kappa B$-tk-luc2 cells. SAHA-induced NF- $\kappa$ B/DNA binding activity was inhibited with the transfection of $\mathrm{pI}-\kappa \mathrm{B} \alpha \mathrm{M}$ in Huh7/NF- $\mathrm{B}-t k-l u c 2$ cells (Fig. 3A). Cell viability after SAHA treatment was significantly decreased in $\mathrm{Huh} 7 / \mathrm{NF}-\kappa \mathrm{B}-$ $t k$-luc 2 cells transfected with $\mathrm{pI}-\kappa \mathrm{B} \alpha \mathrm{M}$ as compared with that transfected with empty vector (Fig. 3B). Apoptosis based on the DNA fragmentation assay was significantly increased in the combination group as compared with those of others groups (Fig. 3C). The transfection of pI- $\kappa \mathrm{B} \alpha \mathrm{M}$ inhibited SAHA-induced expression of $\mathrm{NF}-\kappa \mathrm{B}$-regulated downstream effector proteins and increased SAHA-induced apoptoticrelated proteins (Fig. 3C and D).

Sorafenib inhibits $S A H A$-induced $N F-\kappa B$ activity and $N F-\kappa B$ regulated effector proteins expressions via suppression of ERK activation in Huh7/NF- $\kappa B$-tk-luc $2 / r f p$ cells. Intrinsic $\mathrm{NF}-\kappa \mathrm{B}$ activation, SAHA-induced $\mathrm{NF}-\kappa \mathrm{B}$ activity and expressions of downstream effector proteins were suppressed significantly by sorafenib as shown in Fig. 4A-C. Among the inhibitors for signal transduction, i.e., AKT inhibitor, c-Jun $\mathrm{N}$-terminal kinase (JNK) inhibitor, ERK inhibitor and P38 inhibitor, only ERK inhibitor shows similar effect as sorafenib in suppressing SAHA-induced NF- $\kappa \mathrm{B}$ activation (Fig. 4D). Furthermore, SAHA-induced ERK phosphorylation in Huh7/ $\mathrm{NF}-\kappa \mathrm{B}-t k-l u c 2 / r f p$ cells was suppressed by sorafenib as shown in Fig. 4E.

Sorafenib enhances therapeutic efficacy of SAHA in Huh7/ $N F-\kappa B$-tk-luc2/rfp tumor-bearing mice. Experimental design for the study in vivo is shown in Fig. 5. Though the tumor volumes of SAHA-treated mice were smaller as compared with those of the control, no significant difference was found. Both sorafenib-treated and combination groups had significantly smaller tumor volumes throughout the experimental period until day 21 as compared with those of the control. Notably, the highest tumor suppression was found in the combination group (Fig. 6A). The viable tumor cell growth was evaluated with 
A
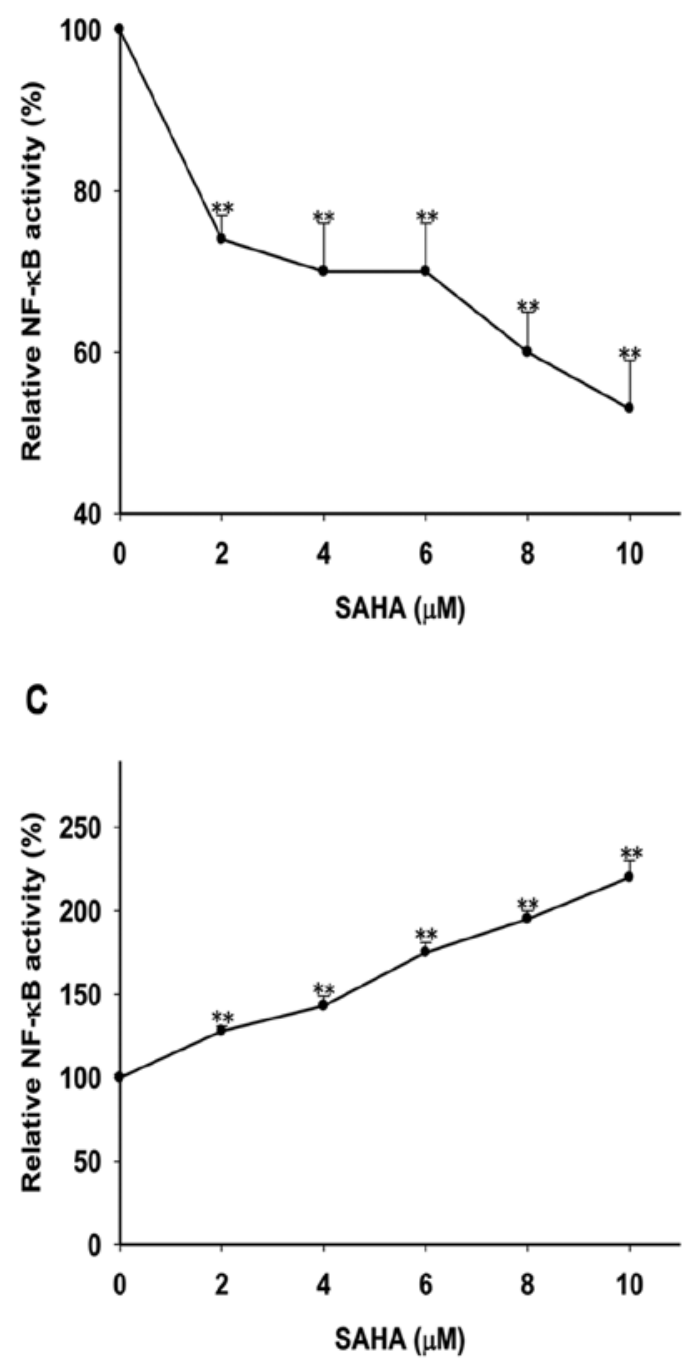

B
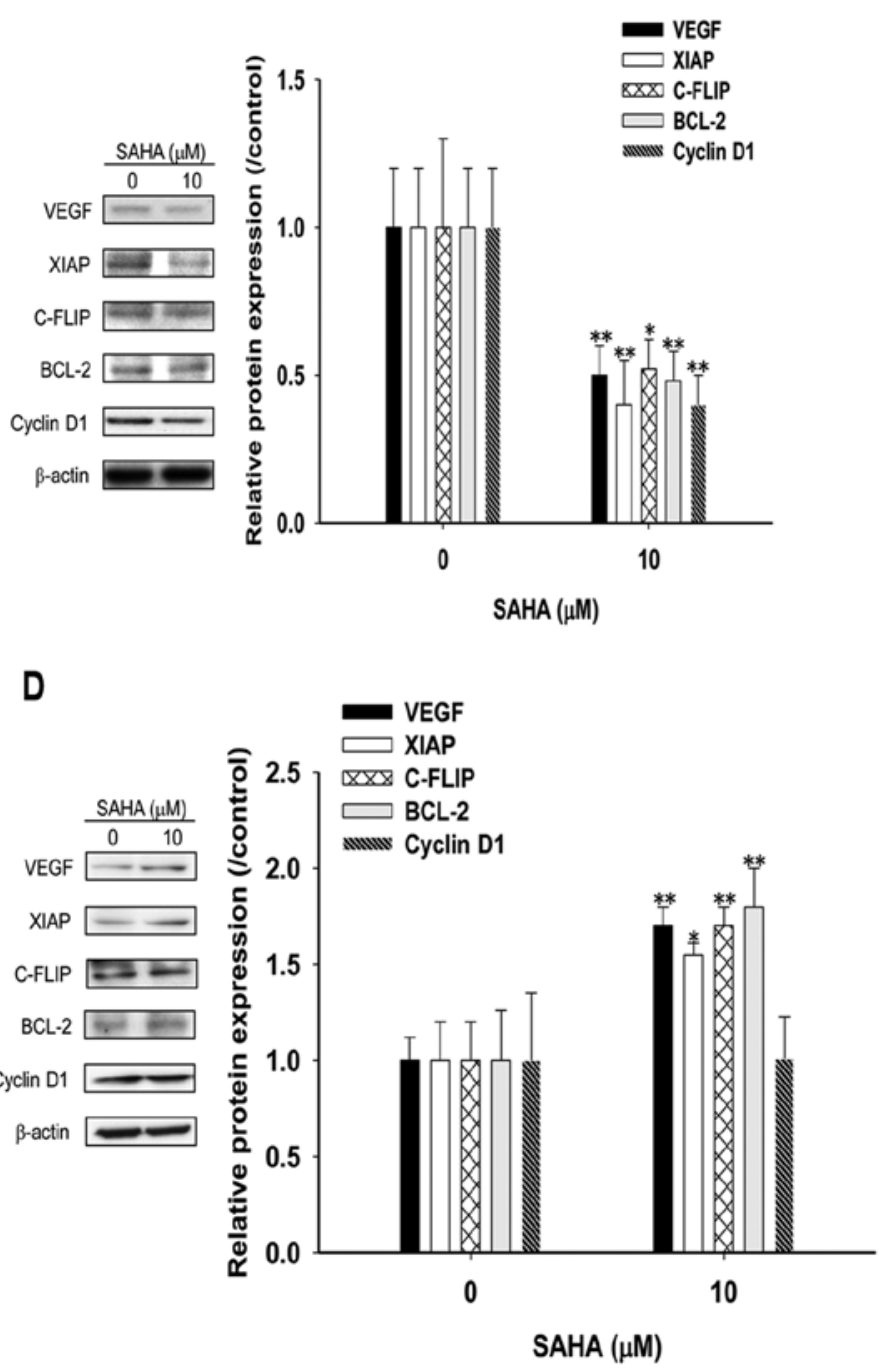

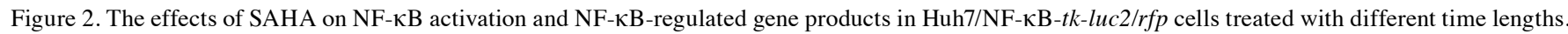
(A) Huh7/NF- $\mathrm{BB}-t k-l u c 2 / r f p$ cells were treated with different concentrations $(0-10 \mu \mathrm{M})$ of SAHA for $24 \mathrm{~h}$. Bioluminescent imaging (BLI) was used to evaluate NF- $\kappa$ B activation. NF- $\kappa$ B activity was inhibited by SAHA in a dose-dependent manner. (B) Expressions of NF- $\kappa$ B-regulated oncogenic proteins were suppressed by SAHA treatment $(10 \mu \mathrm{M}$ for $24 \mathrm{~h})$. (C) Huh7/NF- $\kappa \mathrm{B}-t k-l u c 2 / r f p$ cells were treated with different concentrations $(0-10 \mu \mathrm{M})$ of SAHA for $48 \mathrm{~h}$. NF- $\mathrm{KB}$ activity was increased by SAHA treatment in a dose-dependent manner. (D) Expressions of NF- $\kappa \mathrm{B}-$-regulated oncogenic proteins were increased (except cyclin D1) by SAHA treatment $(10 \mu \mathrm{M}$ for $48 \mathrm{~h}) .\left(\mathrm{p}<0.05,{ }^{* *} \mathrm{p}<0.01\right.$ as compared with that of the control).

RFPI once a week. The emitted photon flux correlates well with the number of viable tumor cells (13). The results demonstrated in Fig. 6B were similar to those shown in Fig. 6A. Since the $\mathrm{NF}-\kappa \mathrm{B}$ level could be increased by SAHA treatment for $48 \mathrm{~h}$, the NF- $\kappa \mathrm{B}$ activation inside the tumor was observed by BLI once a week. The higher photon flux represents the more intense $\mathrm{NF}-\kappa \mathrm{B}$ activity (20). SAHA significantly increased the $N F-\kappa B$ activity as compared with that of the control, but the increase of $\mathrm{NF}-\kappa \mathrm{B}$ activity could be suppressed by sorafenib as shown in the combination group (Fig. 6C). Simultaneous imaging of living tumor cells and NF- $\kappa \mathrm{B}$ activity by RFPI and BLI, respectively, was shown in Fig. 6D. In addition, the uptake of ${ }^{131}$ I-FIAU in tumors, which represented the NF- $\kappa$ B activity, assayed by whole-body autoradiography (13) were also shown to be the most prominent in SAHA-treated mice. Lower uptake of ${ }^{131} \mathrm{I}$-FIAU in sorafenib-treated and combination groups than that of the control was found (Fig. 7A). Furthermore, sorafenib not only inhibited SAHA-induced $\mathrm{NF}-\kappa \mathrm{B} / \mathrm{DNA}$ binding activity, but expression of oncogenic proteins as well, while enhanced expression of SAHA-induced pro-apoptotic proteins by ex vivo western blotting (Fig. 7C).

\section{Discussion}

HDACs including HDAC 1, 3, 8 (class I) and 6 (class IIB) have been shown to correlate with $\mathrm{HCC}$ progression, and all of these enzymes can be inhibited by SAHA (23). NF- $\kappa \mathrm{B}$ activity in the renal cell carcinoma treated with low concentration $(500 \mathrm{nM})$ of SAHA for $24-36 \mathrm{~h}$ could be induced by 1.35- to 1.8-fold above the control (11). NF- $\kappa \mathrm{B}$ has also been reported to be related to chemoresistance through enhancing tumor proliferation, anti-apoptosis, and invasiveness (24). 
A

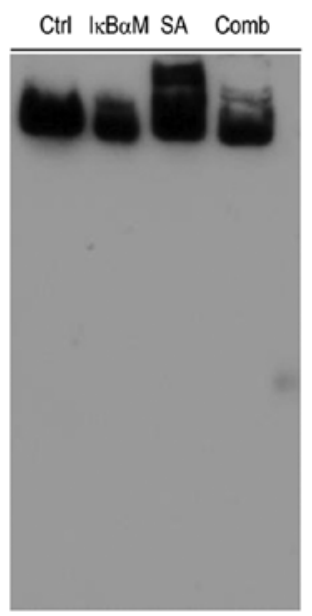

C

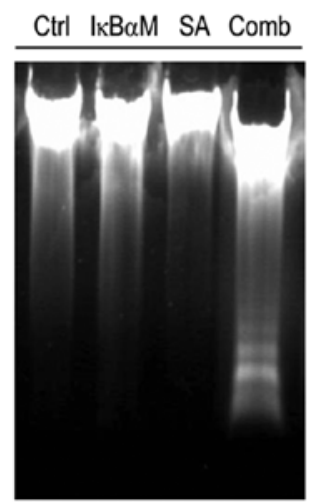

Ctrl=Empty vector
B

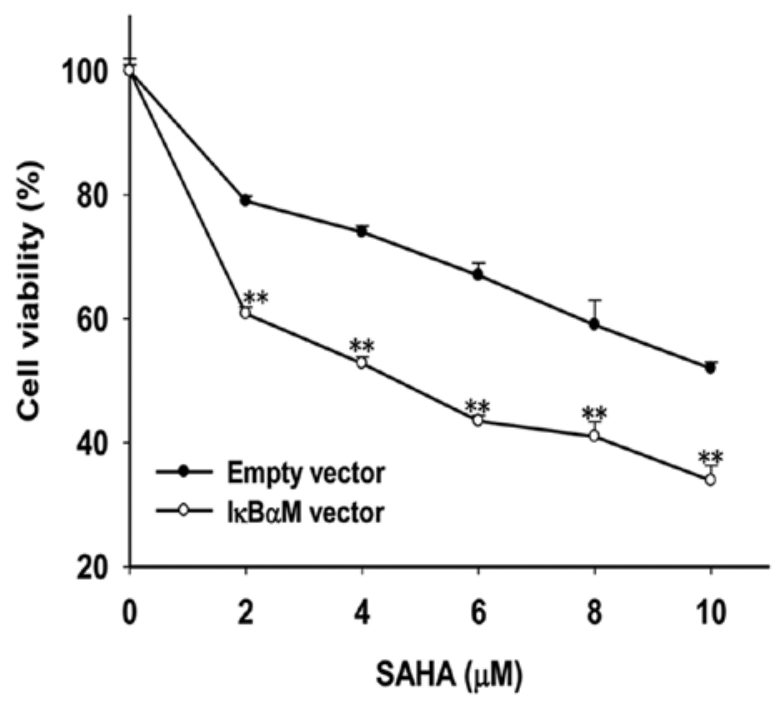

D

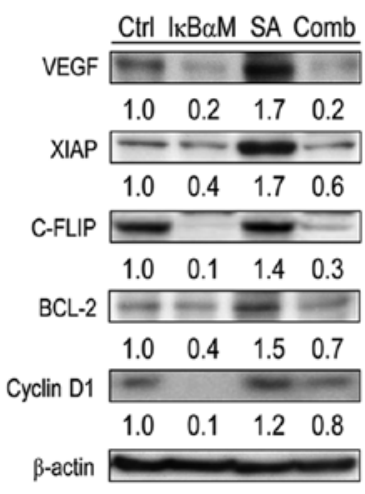

Figure 3. Inhibition of NF- $\kappa B$ activity enhances cytotoxicity of Huh7/NF- $\kappa B-t k-l u c 2 / r f p$ cells by SAHA. (A) Electrophoretic mobility shift assay (EMSA) was

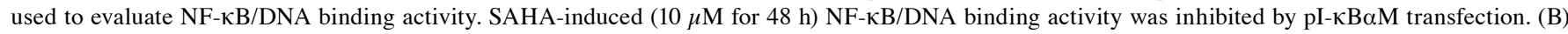
Cells transfected with pI- $\mathrm{\kappa B} \alpha \mathrm{M}$ significantly increased SAHA-induced cytotoxicity. (C) The DNA fragmentation was the most prominent in the combination group as compared with those of other groups. (D) Expressions of NF- $\mathrm{KB}$-regulated oncogenic proteins and pro-apoptotic proteins induced by SAHA were inhibited and enhanced, respectively, by $\mathrm{pI}-\mathrm{\kappa B} \alpha \mathrm{M}$ transfection. Ctrl, control transfected with empty vector; SA, SAHA; Comb, combination.

Here we used high SAHA concentration $(10 \mu \mathrm{M})$ instead of $2.5-5 \mu \mathrm{M}$ as used in most literature $(23,25,26)$, and longer treatment time $(48 \mathrm{~h})$ to achieve higher cytotoxicity for HCC cells (Fig. 1A and B). This strategy resulted in 2-fold increase in NF- $\kappa \mathrm{B}$ activity as compared to that of the control (Figs. 2C, $4 \mathrm{~A}$ and 4D). As a result, the subsequent increased expressions of NF- $\mathrm{NB}$-regulated oncogenic proteins (Figs. 2D, 4C and 7C), which may hamper treatment efficacy, made it a concern when adopting high dose SAHA to treat HCC in clinic. Notably, cancer cells treated with short-term (24 h) SAHA suppressed NF- $\kappa \mathrm{B}$ activity in a dose-dependent manner as shown in Fig. 2A. This was also observed with other cancer cell lines $(11,26)$. Though the preclinical and clinical phase I evidence indicate that HDAC inhibition is effective against various cancer cell lines (8), the potential menace of $N F-\kappa B$ activation after heavily pre-treated solid or hematologic malignancy should be addressed. In our previous studies, we have shown that sorafenib could be used as an NF- $\kappa \mathrm{B}$ inhibitor to suppress constitutive and induced $\mathrm{NF}-\kappa \mathrm{B}$ activity $(13,21)$. Here we demonstrated that $\mathrm{NF}-\kappa \mathrm{B}$ activity and expressions of its regulated oncogenic proteins were significantly induced

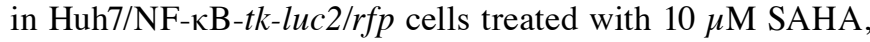
which was equivalent to the maximal clinical dosage (27), for $48 \mathrm{~h}$ but could be suppressed by $10 \mu \mathrm{M}$ sorafenib (Fig. 4). Since combination of sorafenib and SAHA results in the better therapeutic efficacy both in vitro and in vivo (Figs. 1A and 6A), this approach may be a potential strategy for the treatment of $\mathrm{HCC}$ in clinic. Combination of low dose (500 nM) SAHA and sorafenib $(3 \mu \mathrm{M})$ has been reported to kill HCC synergistically through the inhibition of cellular FLICE-like inhibitory protein (c-FLIP) and induction of cluster of differentiation 95 (CD95), the latter is ceramide-PP2A-reactive oxygen species-(ROS) dependent $(11,28,29)$. c-FLIP expression in HCC cells could be suppressed by the treatment of high dose $(2-10 \mu \mathrm{M})$ short- 


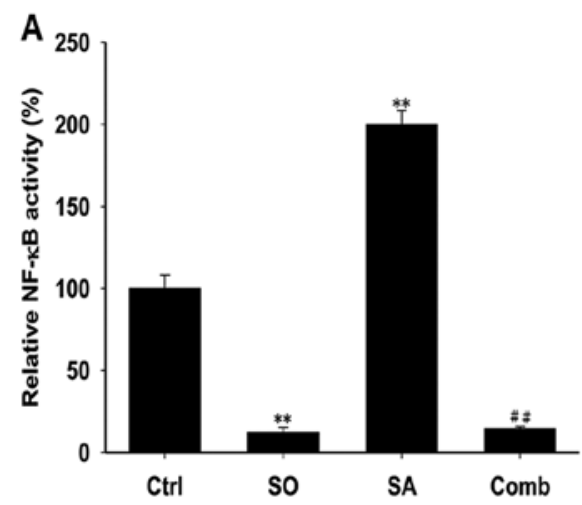

C
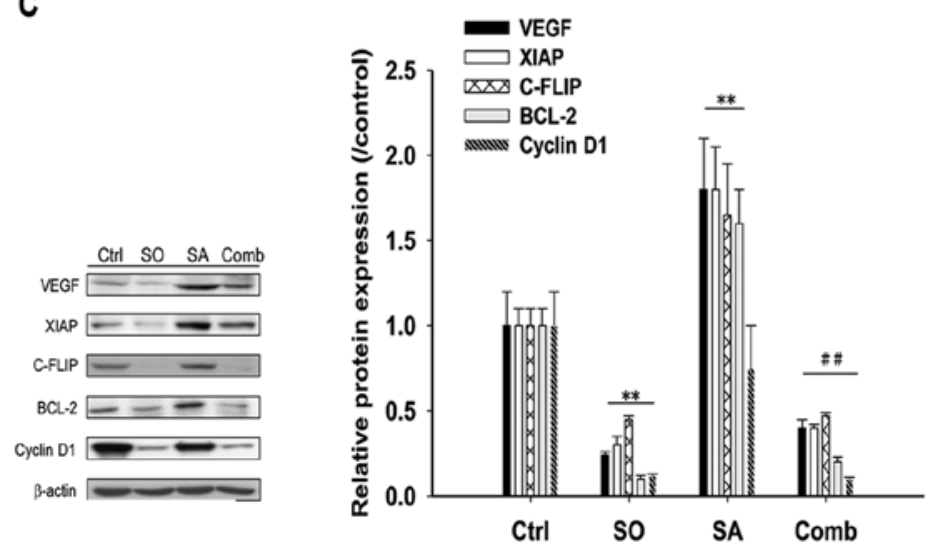

D
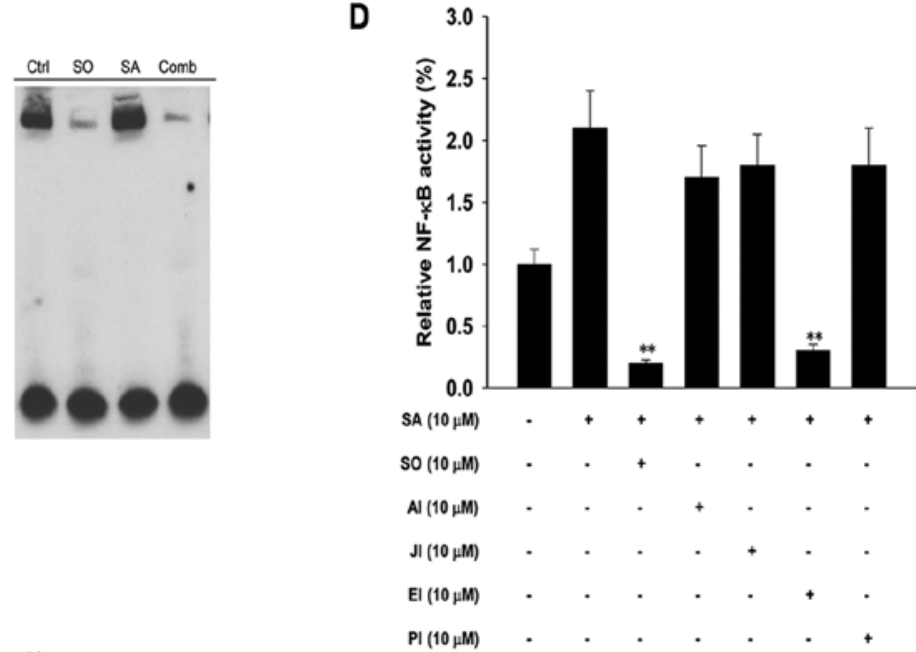

E

Figure 4. Sorafenib inhibits SAHA-induced NF- $\kappa B$ activation and NF- $\kappa B$-regulated effector proteins expressions via inactivation of ERK/NF- $\kappa B$ pathway in

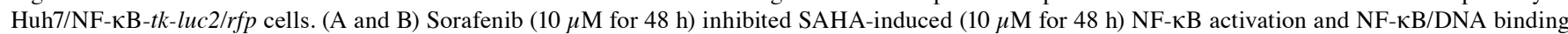
activity. (C) Sorafeinb inhibited SAHA-induced NF-KB-regulated oncogenic proteins expressions ${ }^{* *} \mathrm{p}<0.01$ as compared with that of the control; ${ }^{\# \#} \mathrm{p}<0.01$ as compared with that of SAHA-treated group). (D) Among various singnal transduction inhibitors, only sorafenib and ERK inhibitor inhibited SAHA-induced NF- $\kappa B$ activity ${ }^{* *} \mathrm{p}<0.01$ as compared with that of SAHA-treated group). (E) Sorafenib inhibited SAHA-induced ERK phosphorylation. Ctrl, control; SO, sorafenib; SA, SAHA; Comb, combination; AI, Akt inhibitor; JI, JNK inhibitor; EI, ERK inhibitor; PI, P38 inhibitor.

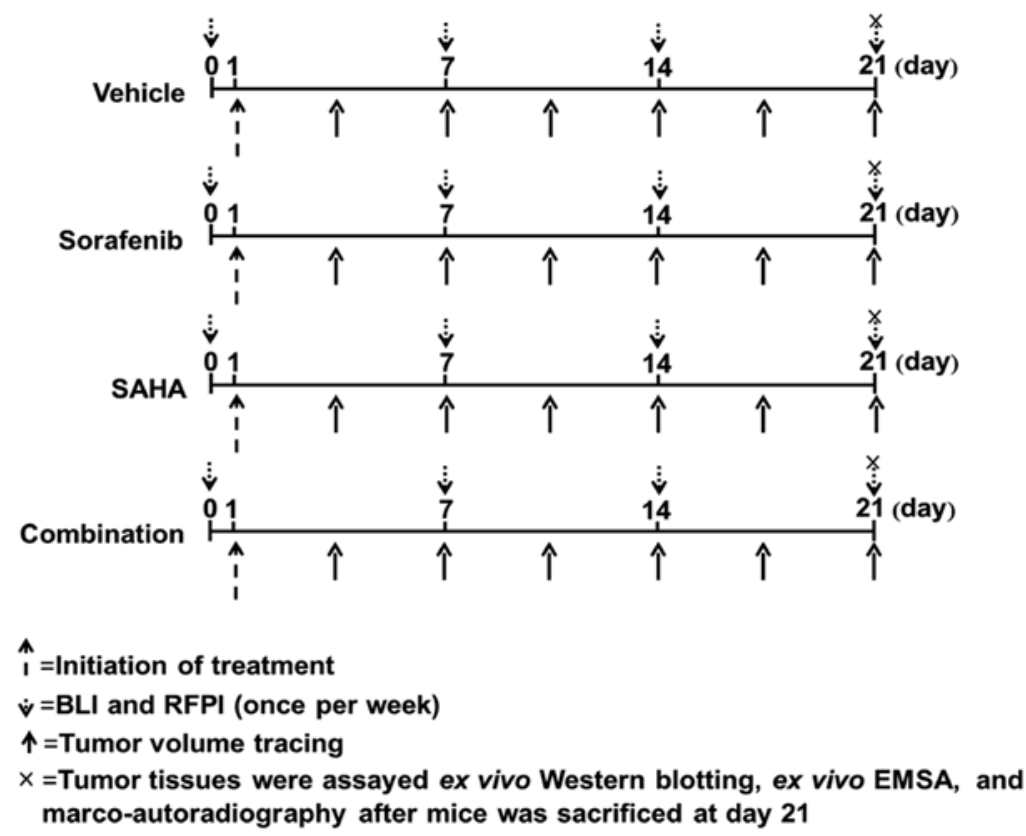

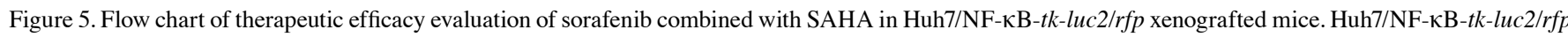
cells were subcutaneously implanted into the right flanks of nude mice. Mice were randomly divided into four groups: vehicle (100 $\mu 1$ PBS with $1 \%$ DMSO by daily gavage), SAHA alone ( $25 \mathrm{mg} / \mathrm{kg} / \mathrm{day}$ x 21 days by gavage), sorafenib alone ( $20 \mathrm{mg} / \mathrm{kg} / \mathrm{day}$ x 21 days by gavage), and combination (SAHA plus sorafenib). Treatments were initiated when tumor size reached about $50 \mathrm{~mm}^{3}$. Tumor growth was monitored with caliper measurement every 3 days, RFPI and BLI was performed once a week. Mice were sacrificed on day 21 for ex vivo western blotting, EMSA, and whole body autoradiography (BLI, bioluminescent imaging; RFPI, red fluorescent protein imaging; $n=6$ in each group). 
A
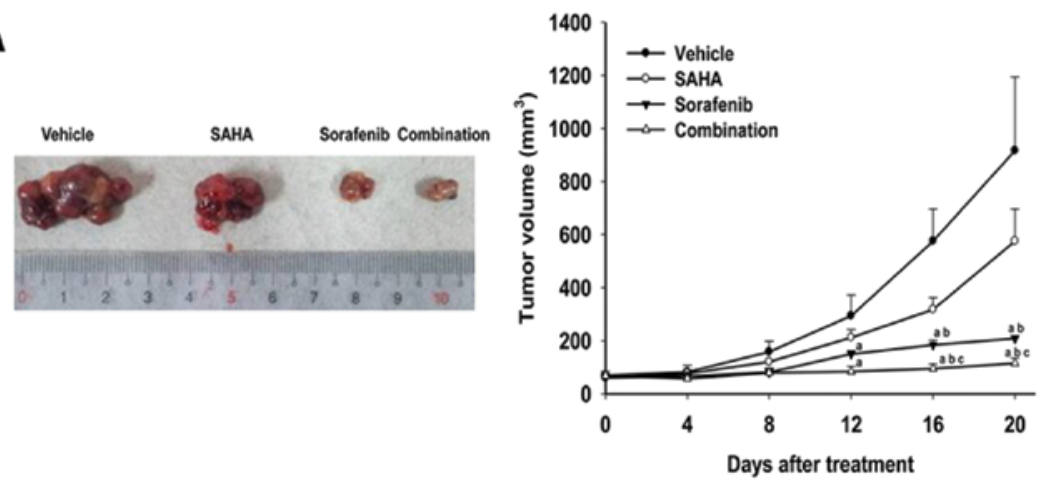

B

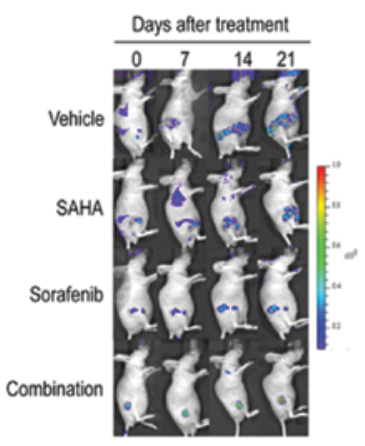

C

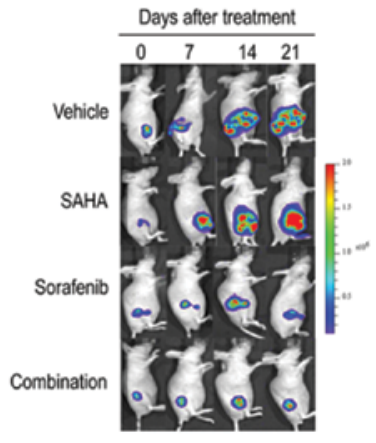

D

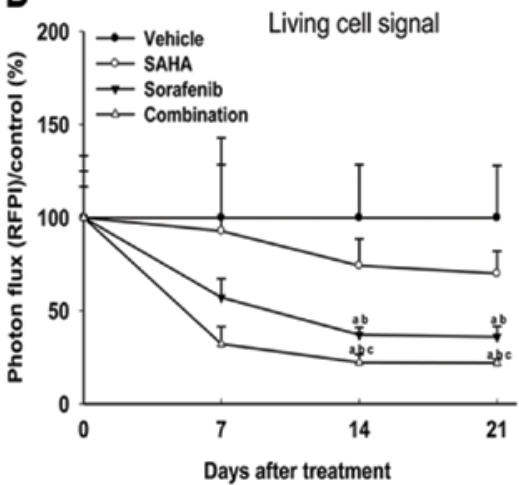

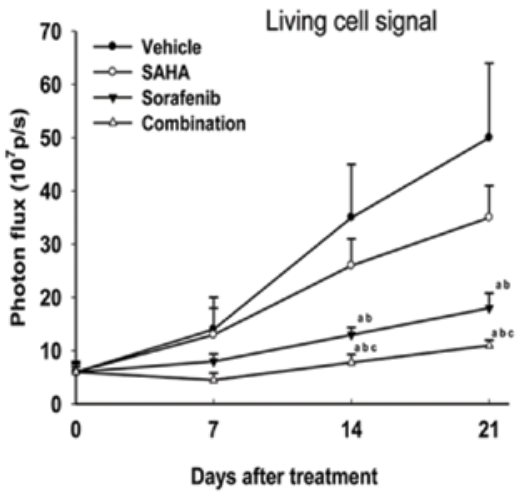
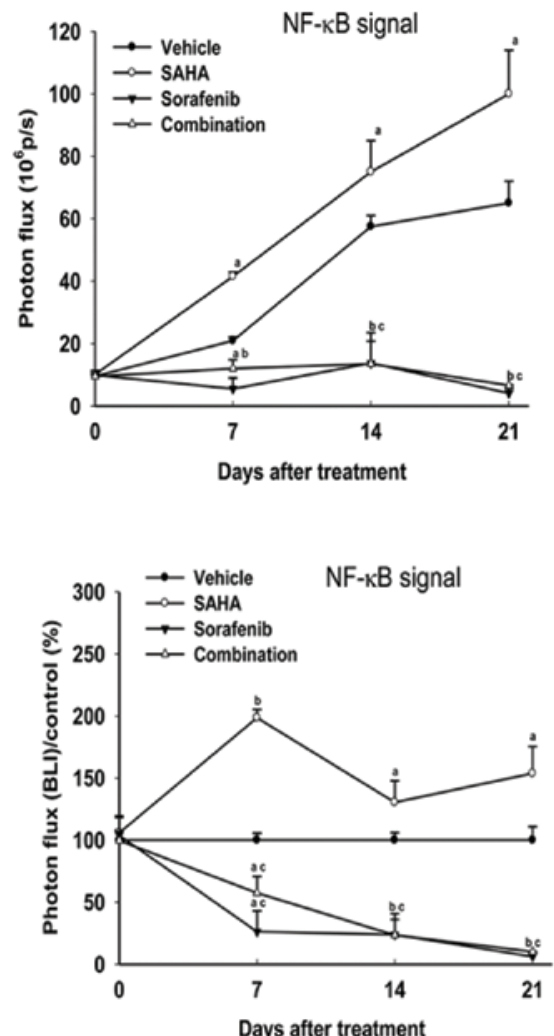

Figure 6. Sorafenib enhances therapeutic efficacy of SAHA in mice with Huh7/NF- $\kappa$ B-tk-luc2/rfp xenografts. (A) Left panel: the photograph of representative tumors obtained from different groups on day 21. Right panel: tumors obtained from sorafenib-treated and combination groups showed smaller and smallest, respectively, by caliper measurement $\left({ }^{a} \mathrm{p}<0.01\right.$ as compared with that of the control, ${ }^{\mathrm{b}} \mathrm{p}<0.01$ as compared with that of SAHA-treated group, ${ }^{\mathrm{c}} \mathrm{p}<0.01$ as compared with that of sorafenib-treated group). (B) Fewer viable tumor cells in sorafenib-treated mice and the fewest in combination group were demonstrated by red fluorescent protein imaging (RFPI) $\left({ }^{\mathrm{a}} \mathrm{p}<0.01\right.$ as compared with that of the control, ${ }^{b} \mathrm{p}<0.01$ as compared with that of SAHA-treated group, ${ }^{\mathrm{c}} \mathrm{p}<0.01$ as compared with that of sorafenib-treated group). (C) The highest NF- $\kappa$ B activation induced by SAHA, and inhibition of SAHA-induced NF- $\kappa$ B activation by sorafenib were revealed by BLI $\left({ }^{a} \mathrm{p}<0.05,{ }^{c} \mathrm{p}<0.01\right.$ as compared with that of the control; ${ }^{b} \mathrm{p}<0.01$ as compared with that of SAHA-treated group). (D) Normalization of RFPI and BLI signal intensities. Left panel: the signals of living cells after treatments were decreased with times as compared with that of the control $\left({ }^{\mathrm{a}} \mathrm{p}<0.01\right.$ as compared with that of the control, ${ }^{b} \mathrm{p}<0.01$ and ${ }^{\mathrm{c}} \mathrm{p}<0.01$ as compared with those of SAHA- and sorafenib-treated groups, respectively). Right panel: the signals of NF- $\kappa$ B were increased and decreased with times in SAHA-treated and sorafenib-treated groups, respectively $\left({ }^{\mathrm{a}} \mathrm{p}<0.05\right.$, ${ }^{\mathrm{b}} \mathrm{p}<0.01$ as compared with that of the control; ${ }^{c} \mathrm{p}<0.01$ as compared with that of SAHA-treated group). BLI, bioluminescent imaging; RFPI, red fluorescent protein imaging. 
A
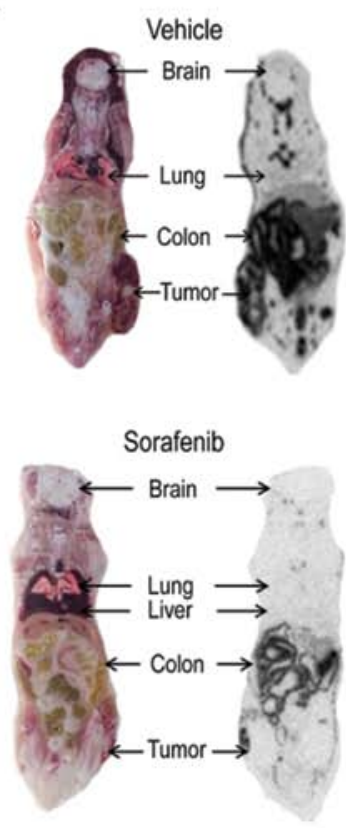

\section{C}

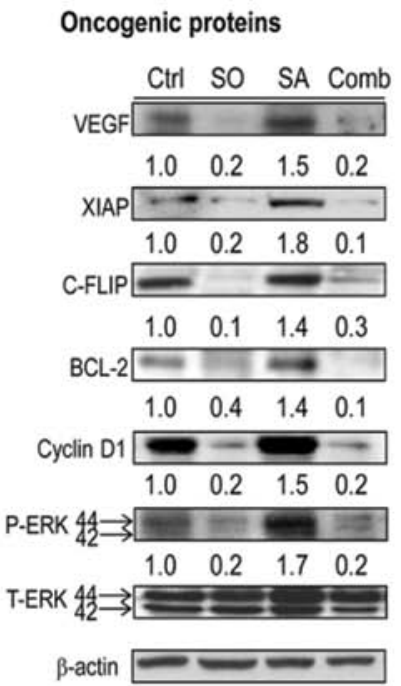

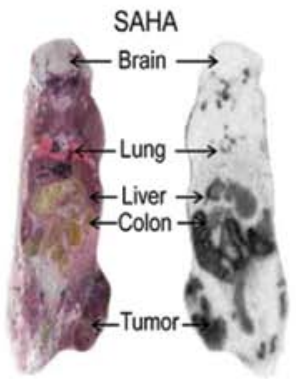

Combination

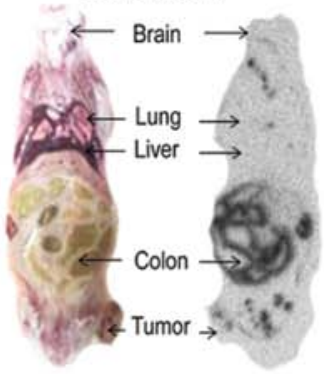

B

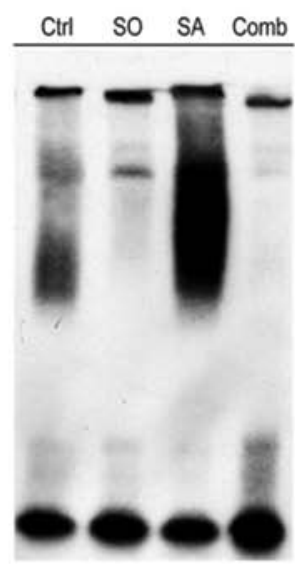

Pro-apoptotic proteins

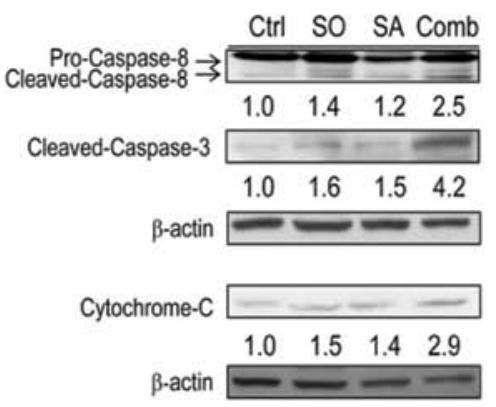

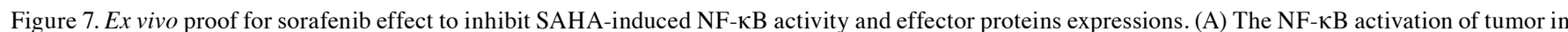
mice was determined with whole-body autoradiography on day 21 . SAHA-induced NF- $\kappa B$ activation was inhibited by combined with sorafenib. (B) NF- $\mathrm{kB} /$ DNA binding activity of tumor was evaluated with ex vivo EMSA on day 21. SAHA-induced NF- $\kappa \mathrm{B} / \mathrm{DNA}$ binding activity was suppressed by sorafenib. (C) The levels of proteins expressions were assayed with ex vivo western blotting on day 21. SAHA-induced expressions of NF- $\mathrm{kB}$-regulated oncogenic proteins were inhibited while expressions of SAHA-induced pro-apoptotic proteins were increased by sorafenib. Ctrl, control; SO, sorafenib; SA, SAHA; Comb, combination.

term (24 h) SAHA (Fig. 2B), but increased after $48 \mathrm{~h}$ treatment (Fig. 2D). c-FLIP expression was also suppressed in HCC cells transfected with pI- $\kappa \mathrm{B} \alpha \mathrm{M}$ (Fig. 3D) or treated with the regular clinical dose $(10 \mu \mathrm{M})$ of sorafenib (Fig. 4C), the latter effectively inhibited constitutive or induced NF- $\kappa \mathrm{B}$ activation in Huh7 cells via suppression of ERK/NF- $\kappa B$ pathway $(13,21)$. Since sorafenib has been reported to eradicate HCC through multiple kinase inhibition (2), we used multiple signal transduction inhibitors to suppress SAHA-induced NF- $\mathrm{NB}$ activity (Fig. 4D). Notably, only ERK inhibitor showed the same effect as sorafenib to suppress SAHA-induced NF- $\kappa$ B activity. Herein we propose that sorafenib inhibits SAHAinduced NF- $\kappa \mathrm{B}$ activity is through the dephosphorylation of ERK both in vitro and in vivo (Figs. 4E and 7C). It is reasonable to deduce that sorafenib enhances anticancer effect of SAHA through the suppression of ERK/NF- $\kappa$ B pathway.

Paradoxical increase of c-FLIP and induced NF- $\kappa$ B activation after high dose, long-term (48 h) SAHA treatment is the niche for sorafenib to be complementary in the combination regimen for cancer treatment. Here we demonstrated the combination strategy worked well in vivo (Figs. 6 and 7). Though the HDAC inhibitor is not yet tested in clinical trial 
for patients with HCC, phase I study for sorafenib combined with SAHA in patients with solid tumors including renal cell carcinoma (RCC) and non-small cell lung cancer has been completed (30). Among 8 patients with RCC, there were 1 partial response and 5 minor responses. The promising result may make future phase II trial more likely. Another small phase II trial exhibited the efficacy of SAHA plus bortezomib in refractory hematologic malignancy (31). However, unfavorable phase II clinical trial results for solid tumors $(32,33)$ and SAHA in combination with $\mathrm{NF}-\kappa \mathrm{B}$ inhibition may be accompanied with intolerable toxicity $(30,31)$.

In our previous study, we demonstrated the visualization of temporal change of intracellular $N F-\kappa B$ signal activation in Huh7/NF- $\kappa \mathrm{B}-t k-l u c 2 / r f p$ tumor-bearing animal model (13). Here the constitutive $\mathrm{NF}-\kappa \mathrm{B}$ signals were found to be increased with the progression of tumor growth in both the control and SAHA treated groups. In contrast, lower NF- $\kappa \mathrm{B}$ activation and decreased expressions of $\mathrm{NF}-\kappa \mathrm{B}$-regulated oncogenic proteins were observed in sorafenib-treated (with or without SAHA) mice, and the tumor growth was inhibited throughout the experiment, particularly in mice treated with SAHA plus sorafenib (Figs. 6C, 6D and 7C). Although tumor growth in mice treated with SAHA alone was found to be slower as compared with that of the control, the NF- $\kappa \mathrm{B}$ activity induced by SAHA allowed tumors to grow more rapidly than mice treated with sorafenib. Therefore, suppression of $\mathrm{NF}-\kappa \mathrm{B}$ activation during HCC treatment with SAHA may be critical for the improvement of therapeutic efficacy.

In conclusion, we found that NF- $\mathrm{B}$ signal can be activated by SAHA with long treatment time $(48 \mathrm{~h})$, and results in increased expressions of $\mathrm{NF}-\kappa \mathrm{B}$-regulated oncogenic proteins. Sorafenib inhibits SAHA-induced NF- $\kappa \mathrm{B}$ activity and expressions of $\mathrm{NF}-\kappa \mathrm{B}$-regulated oncogenic proteins while enhances therapeutic efficacy of SAHA against HCC both in vitro and in vivo through suppression of ERK/NF- $\mathrm{B}$ signaling pathway. Sorafenib combined with SAHA may have potential as a new treatment strategy for the treatment of advanced HCC.

\section{Acknowledgements}

This study was supported by grants NSC 101-2314-B-010045-MY3, NSC 102-2321-B-010-005 from National Science Council, Taipei, Taiwan; and RD2014-012 from National Yang-Ming University Hospital, Yilan, Taiwan. The imaging facility was supported by Taiwan Mouse Clinic.

\section{References}

1. Feng $\mathrm{M}$ and Ben-Josef E: Radiation therapy for hepatocellular carcinoma. Semin Radiat Oncol 21: 271-277, 2011.

2. Zhang X, Yang XR, Huang XW, et al: Sorafenib in treatment of patients with advanced hepatocellular carcinoma: a systematic review. Hepatobiliary Pancreat Dis Int 11: 458-466, 2012

3. Kanno K, Kanno S, Nitta H, et al: Overexpression of histone deacetylase 6 contributes to accelerated migration and invasion activity of hepatocellular carcinoma cells. Oncol Rep 28: 867-873, 2012.

4. Wu J, Du C, Lv Z, et al: The up-regulation of histone deacetylase 8 promotes proliferation and inhibits apoptosis in hepatocellular carcinoma. Dig Dis Sci 58: 3545-3553, 2013.

5. Rikimaru T, Taketomi A, Yamashita Y, et al: Clinical significance of histone deacetylase 1 expression in patients with hepatocellular carcinoma. Oncology 72: 69-74, 2007.
6. Wu LM, Yang Z, Zhou L, et al: Identification of histone deacetylase 3 as a biomarker for tumor recurrence following liver transplantation in $\mathrm{HBV}$-associated hepatocellular carcinoma. PLoS One 5: e14460, 2010.

7. Machado MC, Bellodi-Privato M, Kubrusly MS, et al: Valproic acid inhibits human hepatocellular cancer cells growth in vitro and in vivo. J Exp Ther Oncol 9: 85-92, 2011

8. Coradini D and Speranza A: Histone deacetylase inhibitors for treatment of hepatocellular carcinoma. Acta Pharmacol Sin 26: 1025-1033, 2005.

9. Yoshida K, Sasaki R, Nishimura H, et al: Nuclear factor-kappaB expression as a novel marker of radioresistance in early-stage laryngeal cancer. Head Neck 32: 646-655, 2010.

10. Ni W, Chen B, Zhou G, et al: Overexpressed nuclear BAG-1 in human hepatocellular carcinoma is associated with poor prognosis and resistance to doxorubicin. J Cell Biochem 114: 2120-2130, 2013

11. Zhang G, Park MA, Mitchell C, et al: Vorinostat and sorafenib synergistically kill tumor cells via FLIP suppression and CD95 activation. Clin Cancer Res 14: 5385-5399, 2008.

12. Spratlin JL, Pitts TM, Kulikowski GN, et al: Synergistic activity of histone deacetylase and proteasome inhibition against pancreatic and hepatocellular cancer cell lines. Anticancer Res 31: 1093-1103, 2011.

13. Wang WH, Chiang IT, Liu YC, et al: Simultaneous imaging of temporal changes of NF-kappaB activity and viable tumor cells in Huh7/NF-kappaB-tk-luc2/rfp tumor-bearing mice. In vivo 27: 339-350, 2013.

14. Dai Y, Rahmani M, Dent P and Grant S: Blockade of histone deacetylase inhibitor-induced RelA/p65 acetylation and NF-kappaB activation potentiates apoptosis in leukemia cells through a process mediated by oxidative damage, XIAP downregulation, and c-Jun N-terminal kinase 1 activation. Mol Cell Biol 25: 5429-5444, 2005.

15. Domingo-Domenech J, Pippa R, Tapia M, Gascon P, Bachs O and Bosch M: Inactivation of NF-kappaB by proteasome inhibition contributes to increased apoptosis induced by histone deacetylase inhibitors in human breast cancer cells. Breast Cancer Res Treat 112: 53-62, 2008

16. Dai Y, Guzman ML, Chen S, et al: The NF (nuclear factor)kappaB inhibitor parthenolide interacts with histone deacetylase inhibitors to induce MKK7/JNK1-dependent apoptosis in human acute myeloid leukaemia cells. Br J Haematol 151: 70-83, 2010.

17. Dai Y, Chen S, Wang L, et al: Disruption of IkappaB kinase (IKK)-mediated RelA serine 536 phosphorylation sensitizes human multiple myeloma cells to histone deacetylase (HDAC) inhibitors. J Biol Chem 286: 34036-34050, 2011.

18. Schelman WR, Traynor AM, Holen KD, et al: A phase I study of vorinostat in combination with bortezomib in patients with advanced malignancies. Invest New Drugs 31: 1539-1546, 2013.

19. Deming DA, Ninan J, Bailey HH, et al: A Phase I study of intermittently dosed vorinostat in combination with bortezomib in patients with advanced solid tumors. Invest New Drugs 32: 323-329, 2014.

20. Liu YC, Chiang IT, Hsu FT and Hwang JJ: Using NF-kappaB as a molecular target for theranostics in radiation oncology research. Expert Rev Mol Diagn 12: 139-146, 2012.

21. Chiang IT, Liu YC, Wang WH, et al: Sorafenib inhibits TPA-induced MMP-9 and VEGF expression via suppression of ERK/NF-kappaB pathway in hepatocellular carcinoma cells. In vivo 26: 671-681, 2012.

22. Bankston D, Dumas J, Natero R, et al: A scaleable synthesis of BAY 43-9006 a potent Raf kinase inhibitor for the treatment of cancer. Org Process Res Dev 6: 777-781, 2002.

23. Marks PA and Breslow R: Dimethyl sulfoxide to vorinostat: development of this histone deacetylase inhibitor as an anticancer drug. Nat Biotechnol 25: 84-90, 2007.

24. Li F and Sethi G: Targeting transcription factor NF-kappaB to overcome chemoresistance and radioresistance in cancer therapy. Biochim Biophys Acta 1805: 167-180, 2010.

25. Galimberti S, Canestraro M, Khan R, et al: Vorinostat and bortezomib significantly inhibit WT1 gene expression in MO7-e and P39 cell lines. Leukemia 22: 628-631, 2008.

26. Takada Y, Gillenwater A, Ichikawa H and Aggarwal BB: Suberoylanilide hydroxamic acid potentiates apoptosis, inhibits invasion, and abolishes osteoclastogenesis by suppressing nuclear factor-kappaB activation. J Biol Chem 281: 5612-5622, 2006. 
27. Chen KF, Chen HL, Tai WT, et al: Activation of phosphatidylinositol 3-kinase/Akt signaling pathway mediates acquired resistance to sorafenib in hepatocellular carcinoma cells. J Pharm Exp Ther 337: 155-161, 2011.

28. Park MA, Zhang G, Martin AP, et al: Vorinostat and sorafenib increase ER stress, autophagy and apoptosis via ceramidedependent CD95 and PERK activation. Cancer Biol Ther 7: 1648-1662, 2008.

29. Park MA, Mitchell C, Zhang G, et al: Vorinostat and sorafenib increase CD95 activation in gastrointestinal tumor cells through a $\mathrm{Ca}(2+)$-de novo ceramide-PP2A-reactive oxygen species-dependent signaling pathway. Cancer Res 70: 6313-6324, 2010

30. Dasari A, Gore L, Messersmith WA, et al: A phase I study of sorafenib and vorinostat in patients with advanced solid tumors with expanded cohorts in renal cell carcinoma and non-small cell lung cancer. Invest New Drugs 31: 115-125, 2013.
31. Warlick ED, Cao Q and Miller J: Bortezomib and vorinostat in refractory acute myelogenous leukemia and high-risk myelodysplastic syndromes: produces stable disease but at the cost of high toxicity. Leukemia 27: 1789-1791, 2013.

32. Hoang T, Campbell TC, Zhang C, et al: Vorinostat and bortezomib as third-line therapy in patients with advanced non-small cell lung cancer: a Wisconsin Oncology Network Phase II study. Invest New Drugs 32: 195-199, 2014.

33. Friday BB, Anderson SK, Buckner J, et al: Phase II trial of vorinostat in combination with bortezomib in recurrent glioblastoma: a north central cancer treatment group study. Neuro Oncol 14: 215-221, 2012. 